\title{
Study on Accurate Determination of Volatile Fatty Acids in Rumen Fluid by Capillary Gas Chromatography
}

\author{
Cheng LUO ${ }^{a}$, Suyi CAI, Linyan JIA, Xiang TANG, Ruinan ZHANG, Gang JIA, \\ Hua LI, Jiayong TANG, Guangmang LIU, Caimei WU*b
}

Institute of Animal Nutrition, Key Laboratory for Animal Disease-Resistance Nutrition of Sichuan Province, Key Laboratory for Animal Disease-Resistance Nutrition and Feedstuffs of China Ministry of Agriculture, Sichuan Agricultural University, cheng'du 611130, China

aemail: luocas@foxmail.com, *bemail:zhuomuniao278@163.com

Key Words: Capillary gas chromatography; Rumen fluid; Volatile fatty acids; Internal standard method

\begin{abstract}
In order to obtain accurate results of volatile fatty acids (VFAs) in rumen fluid by capillary gas chromatography (GC), a pretreatment method was firstly conducted by dissolving VFAs in the methanol. An internal standard method (ISM) with crotonic acid as the internal standard was adopted in the detection. The results showed that the reproducibility of VFA (acetic acid, propanoic acid and butyric acid) was enhanced remarkably with methanol added as the solvent. The reproducibility was dependent on both of the VFA concentration and methanol amount. In conclusion, methanol solvent was more suitable than aqueous solvent for VFA accurate detection with ISM by capillary GC.
\end{abstract}

\section{Introduction}

Volatile fatty acids (VFAs) got through rumen fermentation were important energy sources for ruminant animals [1]. The acetic acid, propanoic acid, butyric acid accounted for about $95 \%$ of the total VFAs. Therefore, it was significant to determine acetic acid, propanoic acid and butyric accurately for the rumen fermentation study. In recent years, acetic acid, propanoic acid and butyric acid were detected by GC with packed column or capillary column [1-12] and ion chromatography (IC) [13]. Compared with the longer analysis time of HPLC, IC [13-15] and GC with packed column [1-3], GC with higher efficiency capillary column showed superiority with its rapid analysis (less than $10 \mathrm{~min}$ ) [2]. VFAs detection by capillary column chromatography was proved feasible and accurate [5-9]. HP-INNOWAX capillary column was reported workable to analysis aqueous samples [10]. However, Ma Hui, etc. [11]discovered that capillary GC could not analysis the aqueous samples. Instead of the aqueous solvent, the esterification derivatization of organic solvent could improve the volatility and stability of VFAs. The methyl ester derivatization reduced the smearing phenomenon caused by the organic acid with strong polarity [16]. Expect for the solvent, chromatograph results might be influenced by the sample treatment, volume difference and carrier gas velocity fluctuation. The correction factor (F) in ISM could eliminate the errors. Thus, ISM was prefered in the VFA detection. 2-methyl butyric acid [1], 2-ethyl butyrate [10], isobutyric acid [11] and crotonic acid [12] were ever the available internal standard to determine VFA. Based on the above, methanol was firstly adopted as the solvent in VFAs detection by capillary GC in ISM. A better repeatability was speculated. The method was tested, and the methanol adding amount was optimized. 


\section{Materials and Methods}

\section{Instrument}

Gas chromatograph (Varian CP-3800, manual injection, flame ionization detector, FID, $10 \mu \mathrm{L}$ micro-injector); Legend micro $17 \mathrm{R}$ high speed refrigerated centrifuge (Thermo Electron Corporation, USA); XW-80A vortex mixer (Shanghai Qingpu Huxi Instrument Factory, China).

\section{Chemicals and Reagents}

Acetic acid (AA) and propanoic acid (PA) standards (Purity $\geq 99.5 \%$ ) were obtained from FLUKA Company of USA. Butyric acid (BA) standard (Purity $\geq 99 \%$ ) was obtained from Sigma-Aldrich Co. LLC., USA. Crotonic acid (CA) (Purity $\geq 99 \%$ ) was obtained from Shanghai Kefeng Chemical Reagent Co., Ltd, China. Methanol (HPLC) was purchased from Fisher (USA). Metaphosphoric acid (AR) was obtained from Kelong Co., Ltd., Chengdu, China. ultrapure water was prepared by Milli-Q water purification system.

Preparation of the internal standard solution. The crotonic acid powder was dissolved by ultrapure water into concentration of $210 \mathrm{mmol} / \mathrm{L}$.

25\% (w/v) metaphosphoric acid solution. $25 \mathrm{~g}$ metaphosphoric acid solution powder was dissolved by $100 \mathrm{~mL}$ ultrapure water. The concentration was applied in the whole experiment.

Preparation of standard working solution. Acetic acid, propanoic acid and butyric acid standards were accurately measured diluted by ultrapure water. The concentrations of the acids were 57.65 $\mathrm{mmol} / \mathrm{L}, 53.63 \mathrm{mmol} / \mathrm{L}$ and $17.45 \mathrm{mmol} / \mathrm{L}$, respectively. That is the standard stock solution. The mixed standard stock solution was diluted to 1.0, 0.8, 0.6, 0.4 and 0.2 times separately into EP tubes. Then $1 \mathrm{~mL}$ standard intermediate solution was mixed with $0.2 \mathrm{~mL}$ metaphosphoric acid solution and $40 \mu \mathrm{L}$ crotonic acid solution. After incubation for $30 \mathrm{~min}$ at $4{ }^{\circ} \mathrm{C}$, samples were centrifuged at $12000 \mathrm{rpm}$ for $10 \mathrm{~min}$. The supernatant was blended with methanol at 1:9 (v/v). The solutions were filtered through the $0.22 \mu \mathrm{m}$ microporous membranes for GC analysis.

\section{Sample Extraction}

The cattle rumen fluid was collected $2 \mathrm{hrs}$ after the morning feeding. The rumen fluid samples were mixed with artificial saliva in a ratio of $1: 2(\mathrm{v} / \mathrm{v})$, and then cultured shakily in the water bath. The process should be kept at $39^{\circ} \mathrm{C}$ in the anaerobic environment. After culture for $0,2,4,8,16,24$ and $36 \mathrm{hrs}$, the contents were filtered with nylon bag to $10 \mathrm{~mL}$ centrifuge tube, respectively. Samples were stored at $-20^{\circ} \mathrm{C}$.

\section{Chromatographic Condition}

CP-FFAP chromatographic column: length of $25 \mathrm{~m}$, internal diameter of $0.32 \mathrm{~mm}$ and film thickness of $0.3 \mu \mathrm{m}$. The temperature program set: $100^{\circ} \mathrm{C}$ for $1 \mathrm{~min}, 100{ }^{\circ} \mathrm{C}-190{ }^{\circ} \mathrm{C}$ increasing by $20{ }^{\circ} \mathrm{C} / \mathrm{min}, 190{ }^{\circ} \mathrm{C}$ for $3 \mathrm{~min}$. The total analysis time is $7.5 \mathrm{~min}$. Injection port temperature, $220{ }^{\circ} \mathrm{C}$; Injection volume, $1 \mu \mathrm{L}$; split ratio, 50:1; injection way, manual injection; detector temperature, $250{ }^{\circ} \mathrm{C}$; carrier gas $\mathrm{N}_{2}$ (purity $\geq 99.998 \%$ ) flow, $1 \mathrm{~mL} / \mathrm{min}, \mathrm{H}_{2}$ (purity $\geq 99.998 \%$ ) flow, $40 \mathrm{~mL} / \mathrm{min}$, air flow, $450 \mathrm{~mL} / \mathrm{min}$, make up gas $\mathrm{N}_{2}$ flow, $35 \mathrm{~mL} / \mathrm{min}$.

\section{Methanol addition effect on VFA detection}

$5 \mathrm{~mL}$ thawed rumen fluid was centrifuged at $4000 \mathrm{rpm}$ for $10 \mathrm{~min} .1 \mathrm{~mL}\left(\mathrm{v}_{0}\right)$ supernatant was mixed with $0.2 \mathrm{~mL}\left(\mathrm{v}_{1}\right)$ metaphosphoric acid solution for deproteinization. $40 \mu \mathrm{L}\left(\mathrm{v}_{4}\right)$ crotonic acid solution was added to the above mixture. After incubated at $4{ }^{\circ} \mathrm{C}$ for $30 \mathrm{~min}$, the samples were centrifuged at $12000 \mathrm{rpm}$ for $10 \mathrm{~min}$. $0.1 \mathrm{~mL}\left(\mathrm{v}_{2}\right)$ supernatant was blended with $0.9 \mathrm{~mL}\left(\mathrm{v}_{3}\right)$ methanol. The mixtures were centrifuged as above and filtered through the $0.22 \mu \mathrm{m}$ microporous membranes for detection. The contents of acetic, propanoic and butyric acid in the rumen fluid samples were calculated by the following equation. The volumes can be changed proportionally. The concentrations of the acids detected by GC were represented by $\mathrm{X}$.

$$
\text { Concentration of VFA }(\mathrm{mmol} / \mathrm{L})=\frac{X \times\left(V_{2}+V_{3}\right) \times\left(V_{0}+V_{1}+V_{4}\right)}{V_{2} \times V_{0}}
$$

Five parallel standard and rumen fluid samples were treated as ISM for reproducibility detection. Analogously, five ESM samples in aqueous solvent were conducted. $5 \mathrm{~mL}$ identical 
sample was centrifuged at $4000 \mathrm{rpm}$ for $10 \mathrm{~min} .1 \mathrm{~mL}\left(\mathrm{v}_{0}\right)$ supernatant was mixed with $0.2 \mathrm{~mL}\left(\mathrm{v}_{1}\right)$ metaphosphoric acid solution without crotonic acid added. After incubation for deproteinization and centrifugation, samples were centrifuged for detection.

\section{ISM with methanol addition Confirmation}

The ISM with methanol added is confirmed through the linearity, precision and accuracy detection. The linearity was measured by the five standard working solutions. In a concentration as the abscissa (y), the peak area ratio of acetic, propanoic or butyric acid to crotonic acid as the ordinate (x), the standard curve of ISM was obtained. Five repeated rumen fluid samples of two concentrations were detected for the method precision. The VFA concentration in sample A was low, while that in sample B was relatively high. CVs of the VFA contents were calculated. The recovery rate experiment was conducted by adding the stock solution to the rumen fluid control. Three levels of standard adding amount were used.

\section{Results and Discussion}

\section{Analysis of VFAs in the aqueous and methanol solvent}

Solvent is actually a concern for chromatography detection. VFA detection reproducibility was greatly influenced by solvent and the chromatography column [10] [11]. The superiority of methanol solvent was discussed here. The VFA chromatograms of the standard and rumen fluid sample in the aqueous and methanol solvents are shown in Figure 1. The concentrations of the three acids in Figure 1a were 5.765, 5.363, $1.745 \mathrm{mmol} / \mathrm{L}$, while those in Figure 1c were 4.649, 4.325, $1.470 \mathrm{mmol} / \mathrm{L}$, respectively. Samples in Figure 1c-d were diluted 10 times by methanol. The CVs of retention time and peak area of acetic acid, propanoic acid, butyric acid are shown in Table 2.

a
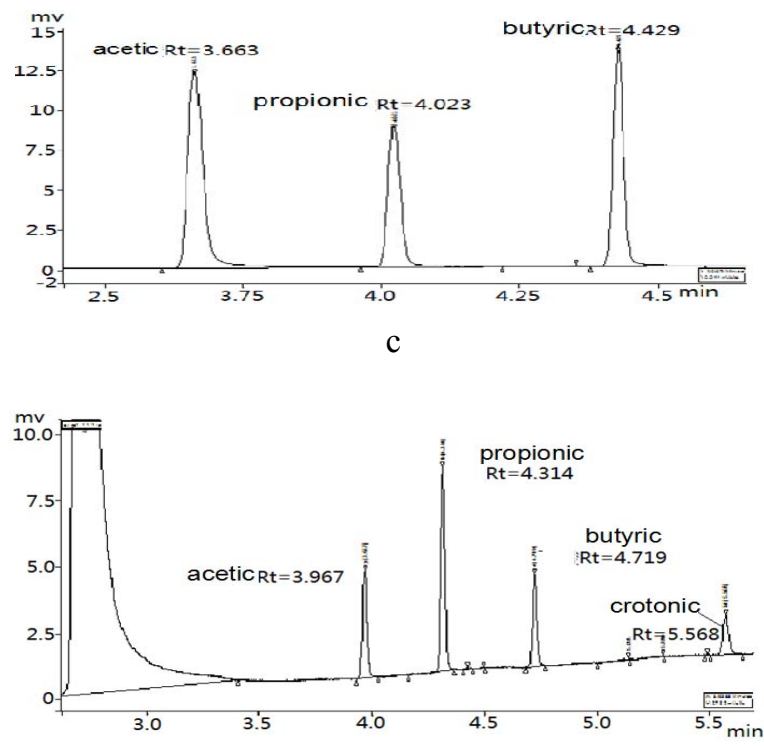

b

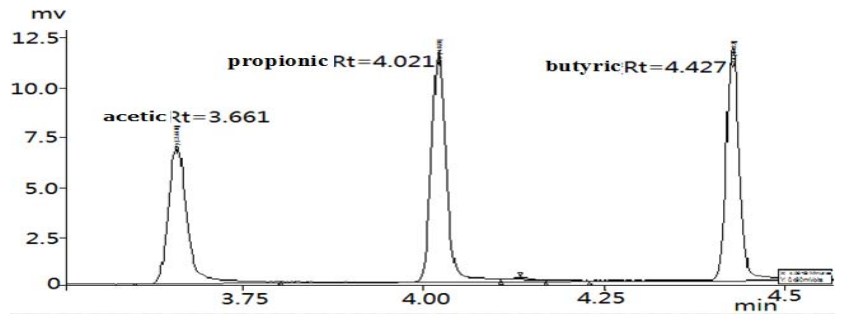

d

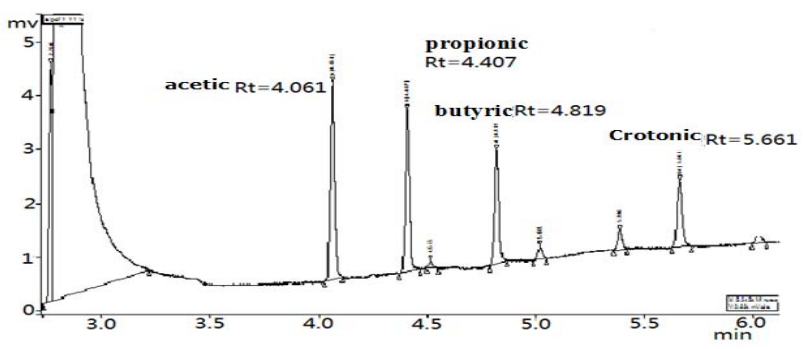

Figure 1. The VFA chromatogram of the standard and the rumen fluid in aqueous solvents $(a, b)$ and in the methanol (c, d)

Figure 1 showed that the acetic acid, propanoic acid and butyric acid in the standard and rumen fluid could be effectively separated. However, the peaks in the aqueous solvent (Figure 1a, 1b) appeared the smearing phenomenon. Narrow peaks of VFAs with high resolution were obtained in the methanol. As shown in Table 1, all the CVs of retention time of the acids were small. The perfect reproducibility could be gotten in the changed concentration of samples and the chromatographic conditions. In the contrast, the CVs of the peak areas in the aqueous solvent were large. The ISM of applying methanol solvent could improve the reproducibility to some degree. 
Table 1. The reproducibility comparison in aqueous and in methanol solution

\begin{tabular}{|c|c|c|c|c|c|c|c|}
\hline \multirow{2}{*}{\multicolumn{2}{|c|}{ Contents }} & \multicolumn{3}{|c|}{ Retention time (min) } & \multicolumn{3}{|c|}{ Areas } \\
\hline & & AA & PA & $\mathrm{BA}$ & $\mathrm{AA}$ & $\mathrm{PA}$ & $\mathrm{BA}$ \\
\hline Aqueous & Values & $3.670 \pm 0.002$ & $4.021 \pm 0.002$ & $4.427 \pm 0.002$ & $3668.6 \pm 763.4$ & $9250.8 \pm 1204.9$ & $6789.6 \pm 1390.4$ \\
\hline solution & $\mathrm{CV}$ & 0.056 & 0.045 & 0.047 & 20.81 & 13.03 & 20.48 \\
\hline Methanol & $\begin{array}{c}(\%) \\
\text { Values }\end{array}$ & $3.966 \pm 0.001$ & $4.313 \pm 0.001$ & $4.720 \pm 0.002$ & $4521.6 \pm 246.1$ & $8886.2 \pm 360.2$ & $4827.6 \pm 249.5$ \\
\hline solution & $\begin{array}{l}\mathrm{CV} \\
(\%)\end{array}$ & 0.018 & 0.030 & 0.032 & 5.44 & 4.05 & 5.17 \\
\hline
\end{tabular}

Note:AA, PA, BA were identified respectively as acetic acid, propionic acid, butyric acid

The analysis reproducibility and stablity of samples in aqueous solution was relatively poor than that in the methanol solution. One of the reasons has been mentioned by Ma Hui that the aqueous samples can not be analyzed by capillary column [11]. In addition, FID of gas chromatography has no response to water. However, the large amount of water solvent in the detector should be removed by the tail blowing gas. The ratio and flow velocity of the carrier gas and tail blowing influence performance and stability of the ionized gas. Thus, the analysis stability of aqueous samples could be influenced greatly. In comparison, the organic solvents exerted better performance on VFA analysis. Short chain fatty acids in the human large intestine were analyzed well by packed column [1]. Samples were diluted 10 times by a mixture of formic acid and acetone. Similarly, VFA in the environmental aqueous samples treated by diethyl ether were successfully detected by capillary gas chromatography [5]. Esterfication of the organic solvents was considered as the key role in the VFA determination [16]. Esterfication improved the volatility and stability of samples, but also reduced the polarity of the strong polar organic acid. Then the chromatography smearing phenomenon disappeared. Therefore, methanol solvent applied in this experiment increased the analysis reproducibility through the methyl esterification. The esterification is reversible. The organic solvents should be excessive to make the esterification complete. And the sample concentration cannot be diluted under the detection limit. Thus, the adding amount of methanol was discussed later.

\section{ISM with methanol addition confirmation}

With better reproducibility in methanol solvent, the ISM was further confirmed. The regression equations are showed in Table 2 . The results indicated that the linearity of the acetic acid, propanoic acid and butyric acid were favorable in the concentration of $0.693-4.649 \mathrm{mmol} / \mathrm{L}, 0.865-4.325$ $\mathrm{mmol} / \mathrm{L}, 0.281-1.407 \mathrm{mmol} / \mathrm{L}$. The $\mathrm{R}^{2}$ values of the ISM were high and the RSD were low. The recoveries of ISM were demonstrated in Table 3. The ideal recoveries were obtained with methanol solvent in this experimental condition.

Table 2. The regression equations of ISM

\begin{tabular}{cccc}
\hline & Regression Equation & $\mathrm{R}^{2}$ & RSD (\%) \\
\hline Acetic acid & $\mathrm{y}=+0.4449 \mathrm{x}+0.03569$ & 0.9956 & 3.72 \\
Propanoic acid & $\mathrm{y}=+0.9796 \mathrm{x}-0.03023$ & 0.9940 & 3.51 \\
Butyric acid & $\mathrm{y}=+1.6753 \mathrm{x}-0.0875$ & 0.9960 & 6.68 \\
\hline
\end{tabular}

In the relatively lower experimental concentration (contents of acetic acid, propanoic acid and butyric acid were around 9,8 and $3 \mathrm{mmol} / \mathrm{L}$, respectively), the CVs of acids were the minimum 
when the samples were diluted to 5 times by methanol. It was speculated that the methyl esterification reacted completely at this ratio. Reproducibility of VFAs decreased with the increased amount of methanol. When the sample concentration was relatively higher (content of acetic acid, propanoic acid and butyric acid were around 40, 36 and $12 \mathrm{mmol} / \mathrm{L}$, respectively) and ratio of methanol and sample was in 9:1 (v/v), the precision satisfied the analysis requirement. The possible reason was that the methyl esterification occured completely in the linear range of the method. Therefore, suitable ratio methanol can enhance analysis reproducibility in the pretreatment process.

Table 3. The recovery of VFAs in rumen fluids $(n=4)$

\begin{tabular}{ccccccc}
\hline & $\begin{array}{c}\text { Background } \\
\text { amount }(\mathrm{mmol} / \mathrm{L})\end{array}$ & $\begin{array}{c}\text { Stock volumn } \\
(\mathrm{mL})\end{array}$ & $\begin{array}{c}\text { Standard addition } \\
(\mathrm{mmol} / \mathrm{L})\end{array}$ & $\begin{array}{c}\text { Detected values } \\
(\mathrm{mmol} / \mathrm{L})\end{array}$ & $\begin{array}{c}\text { Average } \\
\text { recovery }(\%)\end{array}$ & $\begin{array}{c}\text { RSD } \\
(\%)\end{array}$ \\
\hline \multirow{2}{*}{$\begin{array}{c}\text { Acetic } \\
\text { acid }\end{array}$} & 40.728 & 1 & 28.825 & $69.325 \pm 0.87$ & 99.21 & 1.25 \\
& 27.152 & 2 & 38.433 & $67.641 \pm 0.91$ & 105.35 & 1.35 \\
& 20.360 & 3 & 43.238 & $62.854 \pm 1.13$ & 98.28 & 1.79 \\
Propanoic & 18.655 & 1 & 26.815 & $44.359 \pm 1.13$ & 95.86 & 2.54 \\
acid & 12.437 & 2 & 35.753 & $47.879 \pm 1.32$ & 99.13 & 2.75 \\
& 9.327 & 3 & 40.223 & $50.495 \pm 1.49$ & 102.35 & 2.96 \\
Butyric & 6.822 & 1 & 8.725 & $15.345 \pm 0.55$ & 97.68 & 3.60 \\
acid & 4.545 & 2 & 11.663 & $16.079 \pm 0.55$ & 98.89 & 3.42 \\
& 3.411 & 3 & 13.088 & $16.402 \pm 0.47$ & 99.26 & 2.86 \\
\hline
\end{tabular}

\section{Conclusion}

Methanol solvent enhances the analysis reproducibility of VFAs than the aqueous solvent remarkably. The suitable amount of methanol makes acids methyl esterificated and the concentration is in the liner detection rang. With crotonic acid as the internal standard, the linearity, reproducibility and recovery of the ISM were high. Thus, the methanol preprocess method is suitable for the VFA determination in rumen fluid samples.

\section{Acknowledgement}

This research was financially supported by national experimental teaching demonstration center of animal sciences innovation experiment project and sichuan agriculture university Shuangzhi Plan.

\section{References}

[1] Mcneil N I, Cummings J H, James W P. Short chain fatty acid absorption by the human large intestine. [J]. Gut. 1978, 19:819-822.

[2] Slover H T, Lanza E. Quantitative analysis of food fatty acids by capillary gas chromatography. [J]. Journal of The American Oil Chemists' Society. 1979, 56:933-943.

[3] Francis J. S, Christopher S. M. Determination of volatile fatty acid turnover rates in organic-rich marine sediments. [J]. Marine Chemistry. 1981, 10:233-247. 
[4] Julak J, Stranska E, Rosova V. Blood cultures evaluation by gas chromatography of volatile fatty acids. [J]. Medical Science Monitor. 2000, 6:605-610.

[5] Siedlecka E.M, Kumirska J, Ossowski T. Determination of volatile fatty acids in environmental aqueous samples. [J]. Polish Journal of Environmental Studies. 2008, 17:351-356

[6] Zheng chen, Shengli Cheng, Fadi Li. The influence of different nutritional level of complete diet granular on the volatile fatty acids in rumen liquid of sheep. [J]. Chinese Journal of Animal Science.2012, 48:36-39.

[7] Qingyun Cao, Wuyi Zhou, Guizhou Zhu. The study of determination the volatile fatty acids in the sheep rumen liquid by gas chromatography. [J]. Chinese Journal of Animal Science.2006, 24:26-28.

[8] Licheng Liu, Xiuqing Cao, Dasen Liu. The study of the feasibility that applying capillary gas chromatography to detect VFA of rumen liquid. [J]. Feed Industry. 2008, 29:59-60.

[9] Ximing Wei, Licheng Liu, Weihong Song. Comparison of the result of VFA tested between two different temperature patterns by capillary gas chromatography. [J]. Journal of feed Expo. 2011, 3: 43-45.

[10] Xuezhi Ding, Ruijun Long, Ruifang Dan. A determination method based on gas chromatography for analysis of volatile fatty acids in rumen fluid. [J]. Journal of GanSu Agricultural University. 2006, 41:24-26.

[11] Ma Hui, Yi Hong, Lili Wang. The determination of propanoic acid and acetic acid in fermentation by Gas chromatography. [J]. Feed Industry. 2008, 29:48-50.

[12] Jiang Fang, Jiakun Wang, Jianxin Liu. Study on simultaneous determination of VFAs and lactic acid by using internal standard method. [J]. Chinese Journal of Animal Science. 2009, 45:73-76.

[13] Zhang Ping, Limin Ye, Xiaorong Xiao. A study of analyzing short-chain fat acid by gradient reversed-phase high-performance liquid chromatography. [J]. West China Journal of Stomatology. 2001, 19:294-299.

[14] Qingfang Xu, Yu Zhu, Jianguo Han. The determination of organic acid in the silage alfalfa by High performance liquid chromatography. [J]. Grassland and Turf. 2007, 2:63-67.

[15] Fu Tong, Qingsheng Liu, Zhiying Fan. The study on determination of organic acid in silage by ion chromatography. [J]. Chinese Animal Husbandry and Veterinary Medicine. 2005, 32:16-17.

[16] Xibin Chen, Yanglian Feng. A study of the relationship between VFA production and fermentable organic matter in the rumen. [J]. Chinese Journal of Animal Nutrition. 1996, 2:32-36. 